\title{
HLA-B35, a common genetic trait, in a familial case of Henoch-Schoenlein purpura and Berger's disease
}

\author{
M.C. Pellegrin ${ }^{1}$, L. Matarazzo ${ }^{1}$, E. Neri' ${ }^{2}$, M. Pennesi ${ }^{2}$ and S. Crovella ${ }^{1,2}$ \\ ${ }^{1}$ University of Trieste, Trieste, Italy \\ ${ }^{2}$ Institute for Maternal and Child Health - IRCCS "Burlo Garofolo", Trieste, \\ Italy \\ Corresponding author: M.C. Pellegrin \\ E-mail: mariachiara.pellegrin@gmail.com
}

Genet. Mol. Res. 13 (2): 2669-2673 (2014)

Received March 11, 2013

Accepted January 14, 2014

Published April 8, 2014

DOI http://dx.doi.org/10.4238/2014.April.8.9

\begin{abstract}
Nephritis characterized by IgA mesangial depositions has been described both in Henoch-Schoenlein purpura (HSP) and in Berger's disease (BD), but common genetic traits are still uncertain. We report here the case of two brothers, the first affected by HSP with persistent nephritis and the second by $\mathrm{BD}$, accidentally discovered as silent microhematuria 1 year after HSP onset in the first brother. HLA genotyping demonstrated the presence of HLA-B35 in both patients. Our findings reinforce the need to screen for urinary abnormalities in family members of patients affected by HSP nephritis to identify a silent IgA nephropathy.
\end{abstract}

Key words: IgA nephropathy; Henoch Schoenlein purpura; Berger's disease; HLA-B35 


\section{INTRODUCTION}

Berger's disease (BD) and Henoch-Schoenlein purpura (HSP) have been shown to bear a relationship to each other, since both may be found consecutively in the same patient, in identical twins and even in family groups. Nephritis characterized by IgA mesangial deposition is observed in both forms. Common genetic traits have been progressively studied without any certain results, although the HLA genotype is frequently implicated.

\section{MATERIAL AND METHODS}

We report a family case of $\operatorname{IgA}$ nephropathy (IgAN) occurring in two Caucasian brothers, the first with HSP and the second with BD. We performed HLA genotyping using the Dynal SSP kit (Dynal Biotech Ltd., Wirral, UK), in search of a common genetic trait.

\section{CASE DESCRIPTION}

Patient 1: a 9-year-old boy presented at the emergency room with palpable purpura of the lower limbs after a sore throat and colicky abdominal pain without vomit or diarrhea. While abdomen ultrasound was normal, urinalysis showed hematuria (later confirmed by microscopy as glomerular hematuria, $>10$ red blood cells per high power field) and proteinuria $(>500 \mathrm{mg} / 24 \mathrm{~h})$. Throat swab was negative, excluding the role of streptococcal infection. Further onset of arthralgia of the knees and ankles supported the clinical diagnosis of HSP with cutaneous, articular and renal involvement. Despite steroid therapy, a relapse occurred 2 weeks after onset. Blood tests showed increased IgA levels $(268 \mathrm{mg} / \mathrm{dL})$ with normal C3, and urinalysis demonstrated persistent proteinuria and hematuria with no alterations in renal function or blood pressure. Because of the poor response to steroid therapy, intravenous immunoglobulin was administered with rapid improvement. One year later, given the persistence of microhematuria and proteinuria $(741 \mathrm{mg} / 24 \mathrm{~h})$, a renal biopsy was performed, which revealed IgA deposition in the mesangium.

Patient 2: during a routine visit, the 14-year-old brother of patient 1 showed a positive urine dipstick for hematuria. Confirmation of true isolated glomerular hematuria was obtained by urine microscopic examination ( 5 red blood cells per high-power field). This abnormality persisted at follow-up controls, and after an episode of upper airway infection, the patient presented at the emergency room with "tea-like" urine and back pain. Elevation of serum creatinine $(1.13 \mathrm{mg} / \mathrm{dL})$, hematuria ( $>10$ red blood cells per high-power field) and proteinuria $(>500$ $\mathrm{mg} / 24 \mathrm{~h}$ ) with normal kidney ultrasound and blood pressure demonstrated a moderate renal involvement. Post-streptococcal glomerulonephritis was excluded because of increased serum $\operatorname{IgA}(326 \mathrm{mg} / \mathrm{dL})$ with normal C3 level and negative throat swab. The patient underwent renal biopsy that showed expansion of the mesangial matrix and marked IgA depositions. Treatment with angiotensin-converting enzyme inhibitor was started due to the evidence of proteinuria.

Since the renal histological and immunofluorescence microscopy findings in the first brother were indistinguishable from those seen in the second one, genetic analysis involving HLA typing was performed. DNA was extracted from peripheral blood collected in EDTA. HLA typing (using the Dynal SSP kit) finally demonstrated the presence of HLA-B35 in both patients. 


\section{DISCUSSION}

IgAN is the most common form of chronic glomerulonephritis in children and adults. Macroscopic recurrent hematuria with or without proteinuria is the typical presentation, commonly associated with upper respiratory tract infections. Silent microscopic hematuria can also be found. Normal or elevated serum IgA levels with normal serum C3 levels help to distinguish this disorder from post-streptoccocal glomerulonephritis. Clinical diagnosis is confirmed by renal biopsy, which is able to reveal polymeric IgA1 mesangial depositions with focal and segmental mesangial hypercellularity and matrix expansion, varying degrees of glomerulosclerosis and interstitial fibrosis.

IgAN showed a different clinical spectrum since it has been reported both in $\mathrm{BD}$ and in HSP. While the kidneys are always involved in BD, approximately $50 \%$ of patients develop acute kidney involvement in HSP, varying from asymptomatic microscopic hematuria to severe macroscopic hematuria with proteinuria and even to nephrotic syndrome (Chang et al., 2005; Jauhola et al., 2010). Renal involvement typically occurs in the first three months after onset, more commonly with disease relapse. Renal progressive damage develops in up to $30 \%$ of children with BD (particularly in patients with proteinuria or renal failure at presentation) and in 2-5\% of HSP 15-20 years after the first manifestation of disease, and therefore, a careful longterm follow-up of renal function and blood pressure is mandatory. Although there are cases of rapidly progressive forms, IgAN is an uncommon cause of end-stage renal disease in childhood.

Pathogenesis is still unclear and results from genetic association studies are inconsistent. It has been hypothesized that genetic predisposition and antigen exposure increase circulating IgA levels and disrupt IgG synthesis, predisposing to polymeric IgA deposition in systemic small vessels and glomerular vessels. This interaction between genes and environmental triggers could be confirmed by familial clustering of HSP and BD and by their development within different members of the same family (Levy, 1989; Motoyama and Iitaka, 2005; Zhang et al., 2008). BD and HSP have been described in identical twins and may also be encountered consecutively in the same patient, evolving from HSP to BD (Lilien et al., 1996) or vice versa (Chishiki et al., 2010). Demographic and family studies on IgAN have always focused on the major histocompatibility complex. Recently, genome-wide linkage analysis have suggested a strong linkage of IgAN to the HLA region on chromosome 6p22-23 both in family-based and case-control analyses in the UK white population, with no other association of comparable strength found across the genome (Feehally et al., 2010).

HLA-DRB $1 * 01$ has been found associated with high risk of HSP in Italy and Spain although this antigen was not related to any particular feature of the disease phenotype (Amoroso et al., 1997; Amoli et al., 2001). HLA-DRB1*01 allele is in linkage disequilibrium with HLA-B35, HLA-B14 and HLA-B27 in Caucasian populations. In particular, the HLA-B35 haplotype was previously described as related to an increased predisposition to HSP (Peru et al., 2008), to HSP recurrent forms (Nathwani et al., 1992) and HSP nephritis. All these clinical features were also associated with HLA-B35 in patient 1 . Only the presence of abdominal pain was in contrast to the literature, where no HLA-B antigenic associations have been observed in association with gastrointestinal manifestations (Amoli et al., 2002).

When considering BD, the frequencies of HLA-DR4 and HLA-B35 in the Japanese population (Hiki et al., 1990) are significantly higher in BD than in controls. HLA-B35 has also been reported as a marker of severity and a poor prognostic factor since it was associated 
with end-stage renal failure in IgAN (Alamartine et al., 1991; Doxiadis et al., 2001). In patient 2 , we observed an increase of serum creatinine and proteinuria at disease onset, representing a risk factor for progressive renal damage.

In addition, both our patients developed clinical symptoms in association with an upper respiratory infection with negative throat swab. This type of infection could be fundamental for the development of IgA nephropathy; moreover, HLA-B35 has been reported to be associated with the severity of viral illness (Klein et al., 1994) and possibly with an augmentation in response of cytotoxic T lymphocyte to alloantigens (Burrows et al., 1997).

In conclusion, given the common genetic and environmental trigger, we think that careful clinical monitoring should be considered in other family members, not only in BD history but also in HSP, especially when HSP is recurrent and/or develops into persistent nephritis. Silent BD nephropathy could be identified in the relatives and, if necessary, they could be promptly treated using anti-inflammatory strategies (fish oil, vitamin E), angiotensin-converting enzyme inhibitors, or steroid therapy if severe proteinuria and/or renal insufficiency is present. Early diagnosis and treatment of IgAN in children may bring about important benefits and a favorable prognosis (Bulut et al., 2012).

To our knowledge this is the first report to highlight the association between HLAB35 and IgAN both in HSP and BD. These results suggest a link between the two diseases and reinforce the idea of a common pathogenesis, suggesting a role of HLA-B35 in IgA mesangial deposition. We are aware that our study has a weak point, since we lost the children's parents at follow-up due to social problems, so it was impossible to construct a pedigree and eventually genotype them and other relatives to determine the incidence of HLA-B35 in the family. Moreover, since HLA-B35 was not always positive in other familial studies of IgAN (Montoliu et al., 1990), additional studies are required to uncover other HLA-associated alleles to identify possible genetic loci in IgAN susceptibility and disease severity.

\section{REFERENCES}

Alamartine E, Sabatier JC, Guerin C, Berliet JM, et al. (1991). Prognostic factors in mesangial IgA glomerulonephritis: an extensive study with univariate and multivariate analyses. Am. J. Kidney Dis. 18: 12-19.

Amoli MM, Thomson W, Hajeer AH, Calviño MC, et al. (2001). HLA-DRB1*01 association with Henoch-Schönlein purpura in patients from northwest Spain. J. Rheumatol. 28: 1266-1270.

Amoli MM, Thomson W, Hajeer AH, Calvino MC, et al. (2002). HLA-B35 association with nephritis in Henoch-Schönlein purpura. J. Rheumatol. 29: 948-949.

Amoroso A, Berrino M, Canale L, Coppo R, et al. (1997). Immunogenetics of Henoch-Schöenlein disease. Eur. J. Immunogenet. 24: 323-333.

Bulut IK, Mir S, Sozeri B, Bulut MO, et al. (2012). Outcome results in children with IgA nephropathy: a single center experience. Int. J. Nephrol. Renovasc. Dis. 5: 23-28.

Burrows SR, Silins SL, Khanna R, Burrows JM, et al. (1997). Cross-reactive memory T cells for Epstein-Barr virus augment the alloresponse to common human leukocyte antigens: degenerate recognition of major histocompatibility complex-bound peptide by T cells and its role in alloreactivity. Eur. J. Immunol. 27: 1726-1736.

Chang WL, Yang YH, Wang LC, Lin YT, et al. (2005). Renal manifestations in Henoch-Schönlein purpura: a 10-year clinical study. Pediatr. Nephrol. 20: 1269-1272.

Chishiki M, Kawasaki Y, Kaneko M, Ushijima Y, et al. (2010). A 10-year-old girl with IgA nephropathy who 5 years later developed the characteristic features of Henoch-Schönlein purpura nephritis. Fukushima J. Med. Sci. 56: 157-161.

Doxiadis II, De Lange P, De Vries E, Persijn GG, et al. (2001). Protective and susceptible HLA polymorphisms in IgA nephropathy patients with end-stage renal failure. Tissue Antigens 57: 344-347.

Feehally J, Farrall M, Boland A, Gale DP, et al. (2010). HLA has strongest association with IgA nephropathy in genomewide analysis. J. Am. Soc. Nephrol. 21: 1791-1797. 
Hiki Y, Kobayashi Y, Ookubo M and Kashiwagi N (1990). The role of HLA-DR4 in the long-term prognosis of IgA nephropathy. Nephron 54: 264-265.

Jauhola O, Ronkainen J, Koskimies O, Ala-Houhala M, et al. (2010). Renal manifestations of Henoch-Schönlein purpura in a 6-month prospective study of 223 children. Arch. Dis. Child 95: 877-882.

Klein MR, Keet IP, D’Amaro J, Bende RJ, et al. (1994). Associations between HLA frequencies and pathogenic features of human immunodeficiency virus type 1 infection in seroconverters from the Amsterdam cohort of homosexual men. J. Infect. Dis. 169: 1244-1249.

Levy M (1989). Familial cases of Berger's disease and anaphylactoid purpura: more frequent than previously thought. Am. J. Med. 87: 246-248.

Lilien MR, Donckerwolcke RA and Vroom TM (1996). Henoch-Schöenlein purpura-nephritis followed by IgA-nephritis in 3 children. Ned. Tijdschr. Geneeskd. 140: 316-319.

Montoliu J, Lens XM, Torras A and Revert L (1990). Henoch-Schönlein purpura and IgA nephropathy in father and son. Nephron 54: 77-79.

Motoyama $\mathrm{O}$ and Iitaka K (2005). Familial cases of Henoch-Schönlein purpura in eight families. Pediatr. Int. 47: 612-615.

Nathwani D, Laing RB, Smith CC and Edward N (1992). Recurrent post-infective Henoch-Schönlein syndrome: a genetic influence related to HLA B35? J. Infect. 25: 205-210.

Peru H, Soylemezoglu O, Gonen S, Cetinyurek A, et al. (2008). HLA class 1 associations in Henoch Schönlein purpura: increased and decreased frequencies. Clin. Rheumatol. 27: 5-10.

Zhang Y, Gu W and Mao J (2008). Sibling cases of Henoch-Schönlein purpura in two families and review of literature. Pediatr. Dermatol. 25: 393-395. 